\title{
ADHESIVE BONDING OF ALUMINIUM ALLOY A5754 BY EPOXY RESINS
}

\author{
Ivan MichaleC*, Milan MarôneK \\ Faculty of Materials Science and Technology, Slovak University of Technology, Department of Welding and \\ Foundry, J. Bottu 25, 91724 Trnava, Slovakia \\ * corresponding author: ivan.michalec@stuba.sk
}

ABstRACT. Joining thin sheets of aluminium and its alloys is a promising area in the field of joining materials. Nowadays, joining methods that do not melt the material itself are increasingly being utilised. This paper deals with adhesive bonding of aluminium alloy A5754 by two-component epoxy resins. The results show that joints bonded by Hysol 9466 have appropriate mechanical properties, but that joints bonded by Hysol 9492 have better thermal stability.

KEYwORDS: adhesive bonding, aluminium, fracture.

\section{INTRODUCTION}

Aluminium alloys have a wide area of utilisation, especially in the aircraft and automotive industries. Their properties are also suitable for use in a variety of other industrial applications. The greatest progress with aluminium alloys has been observed in the automotive industry, where the very suitable properties of aluminium alloys are appreciated [1]. Aluminium is very light, corrosion-resistant, can be treated to achieve high strength, and is very easily formable. However, it is quite a complicated material to weld, mainly because of the presence of aluminium oxide $\mathrm{Al}_{2} \mathrm{O}_{3}$ on the surface, and because of the high coefficient of thermal expansion. For this reason, aluminium is increasingly being bonded adhesively [2, 3].

Adhesive bonding offers many advantages over fusion welding methods, e.g. uniform stress distribution, lower structural weight, the possibility to join bulk components, suitability for joining very thin materials, etc. One of the most significant advantages lies in the possibility of joining various combinations of materials that cannot be welded by conventional fusion methods [4, 5].

\section{MATERIALS AND METHODS}

The material used in our study was aluminium alloy A5754 $\left(\mathrm{AlMg}_{3}\right)$. The dimensions of the sheets were $100 \times 30 \times 1.5 \mathrm{~mm}$. The chemical composition of the alloy was measured by JEOL JSM7600F with an EDS/WDS detector, and is documented in Table 1 The mechanical properties of the alloy are presented in Table 2. The experiments were carried out at the Department of Materials Science, Faculty of Materials Science and Technology in Trnava of the Slovak University of Technology.

\subsection{AdHesive BONDING CONDITIONS}

Two different types of two-component epoxy adhesives were used in the experiments (see Table 3). Before

\begin{tabular}{cccccc}
\hline Material & $\mathbf{M g}$ & $\mathbf{S i}$ & $\mathbf{M n}$ & $\mathbf{F e}$ & $\mathbf{A l}$ \\
\hline $\mathbf{A 5 7 5 4}$ & 3.07 & 0.39 & 0.33 & 0.59 & $\mathrm{bal}$. \\
\hline
\end{tabular}

TABLE 1. Chemical composition of A5754 alloy [wt. \%].

\begin{tabular}{ccc}
\hline $\begin{array}{c}\text { Tensile } \\
\text { strength }\end{array}$ & $\begin{array}{c}\text { Yield } \\
\text { strength }\end{array}$ & Ductility \\
\hline $270 \mathrm{MPa}$ & $175 \mathrm{MPa}$ & $15 \%$ \\
\hline
\end{tabular}

TABLE 2. Mechanical properties of A5754 alloy.

\begin{tabular}{ccc}
\hline & Hysol 9466 & Hysol 9492 \\
\hline Resin type & Epoxy & Epoxy \\
\hline Hardener type & Amin & Modified Amin \\
\hline $\begin{array}{c}\text { Mixing ratio } \\
\text { resin : hardener } \\
\text { [vol. \%] }\end{array}$ & $2: 1$ & $2: 1$ \\
\hline
\end{tabular}

TABLE 3. Characteristics of Hysol 9466 and Hysol 9492.

the adhesive bonding, the joints were prepared by grinding with silicon carbide paper up to 240 grit and then decreased with aerosol cleaner. The overlap was $30 \mathrm{~mm}$. A continuous layer of adhesive was coated on both overlap areas to ensure high strength of the joints. The adhesive layer was $0.1 \mathrm{~mm}$ in thickness, and it was controlled by a calliper. The joints were fixed with clamps and cured at room temperature for 48 hours. A schematic drawing of the bonded joints is shown in Fig. 1. The dimensions of the aluminium sheets were $100 \times 30 \times 1.5 \mathrm{~mm}$, and the overlap (bonded area) was $30 \times 30 \mathrm{~mm}$.

\subsection{EXPERIMENTAL METHODS}

Differential scanning calorimetry, thermal gravimetric analysis and static tensile tests were performed on the adhesives. Electron microscopy and static shear tests 


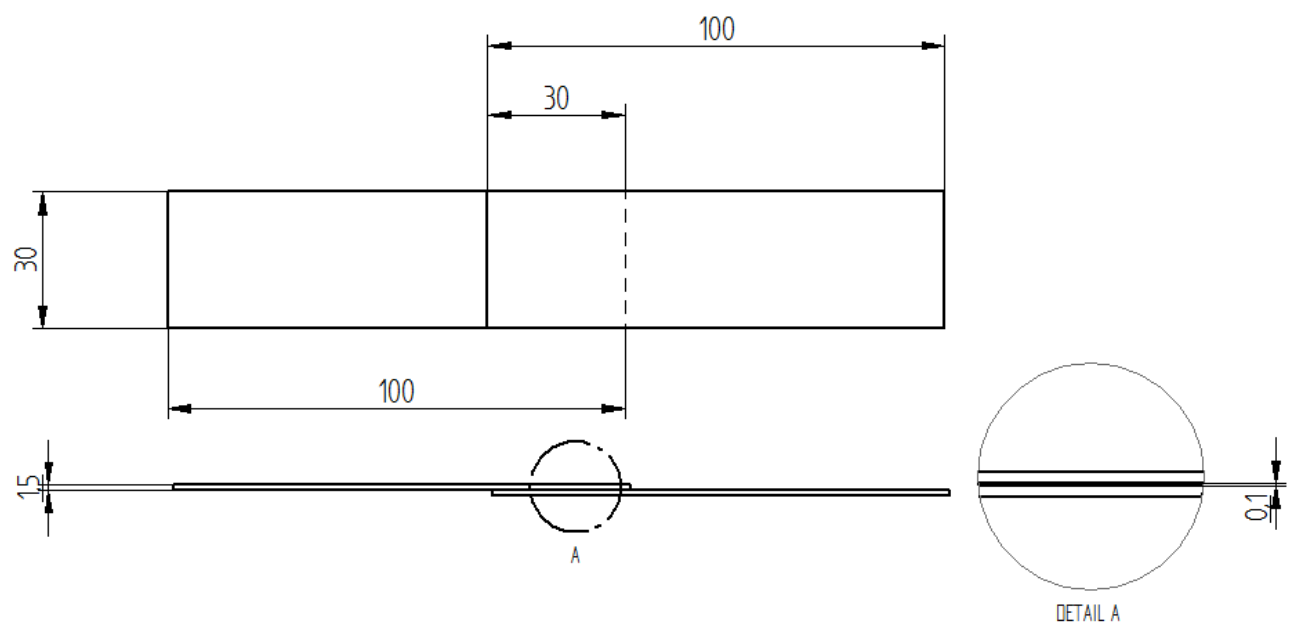

FIGURE 1. Dimensions of the bonded joint

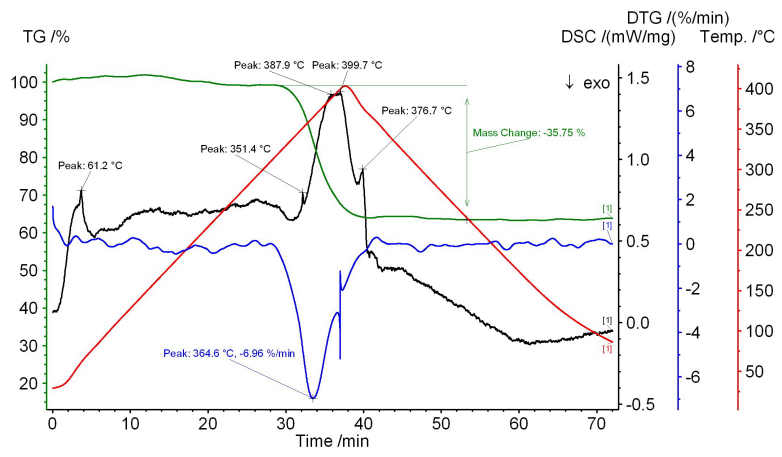

FiguRE 2. DSC analysis of the Hysol 9492 adhesive.

\begin{tabular}{lcc}
\hline & Hysol 9466 & Hysol 9492 \\
\hline Tensile strength & $60 \mathrm{MPa}$ & $56 \mathrm{MPa}$ \\
\hline
\end{tabular}

TABLE 4. Tensile strength of Hysol 9466 and 9492.

were performed on the joints. Differential scanning calorimetry (DSC) was performed on Netzsch STA 409 $\mathrm{C} / \mathrm{CD}$ equipment. Helium with purity of $99.999 \%$ was used as the shielding gas. The heating process started at room temperature and continued up to $400{ }^{\circ} \mathrm{C}$ with a heating rate of $10^{\circ} \mathrm{Cmin}^{-1}$. The static tensile and shear tests were carried out on LABORTECH LabTest $5.250 \mathrm{Sp} 1$ equipment. Each test was repeated on three separate specimens.

\section{Results}

\subsection{Adhesives ANALYSis}

The results of DSC analysis and also the thermal gravimetric analyses are shown in Figs. 2 and 3. The glass transition temperatures were $61.2^{\circ} \mathrm{C}$ for Hysol 9492 and $52.6^{\circ} \mathrm{C}$ for Hysol 9466. Thermal gravimetric analysis revealed that for Hysol 9492 the thermally affected decrease in mass was $35.75 \%$, whereas for Hysol 9466 the decrease was $61.06 \%$. Both mass changes were accompanied by exothermic reactions, and continued

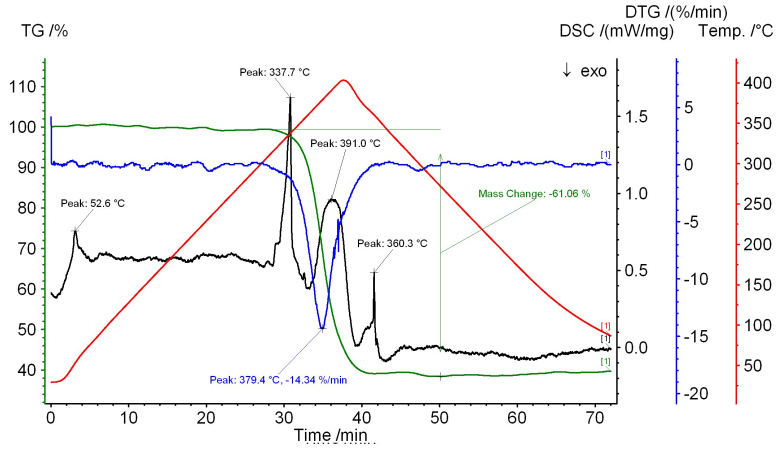

FigURE 3. DSC analysis of the Hysol 9496 adhesive.

\begin{tabular}{lcc}
\hline & Hysol 9466 & Hysol 9492 \\
\hline Force to failure & $6800 \mathrm{~N}$ & $4400 \mathrm{~N}$ \\
\hline Shear strength & $7.6 \mathrm{MPa}$ & $4.9 \mathrm{MPa}$ \\
\hline
\end{tabular}

TABlE 5. Results of shear tests of bonded joints.

even after the heating was stopped. The derivation of the thermal gravimetry showed that the biggest mass decrease for Hysol 9492 was $6.96 \% \mathrm{~min}^{-1}$ at a temperature of $364.6^{\circ} \mathrm{C}$, and the biggest mass decrease was $14.34 \% \mathrm{~min}^{-1}$ at a temperature of $379.4{ }^{\circ} \mathrm{C}$ for Hysol 9466.

Static tensile tests were carried out to obtain the mechanical properties of the adhesives. The adhesives were cured in specially-designed polyethylene forms for 48 hours. Tensile tests were carried out on three separate samples of each adhesive. The results are presented in Table 4

\subsection{AnAlysis OF the JOINTS}

The static shear tests were the first step in an evaluation of the joints. The tests were performed on three separate samples. The conditions for the shear tests were set in accordance with STN EN 10002-1; the speed rate was $2.5 \mathrm{~mm} \mathrm{~min}^{-1}$. The results for 


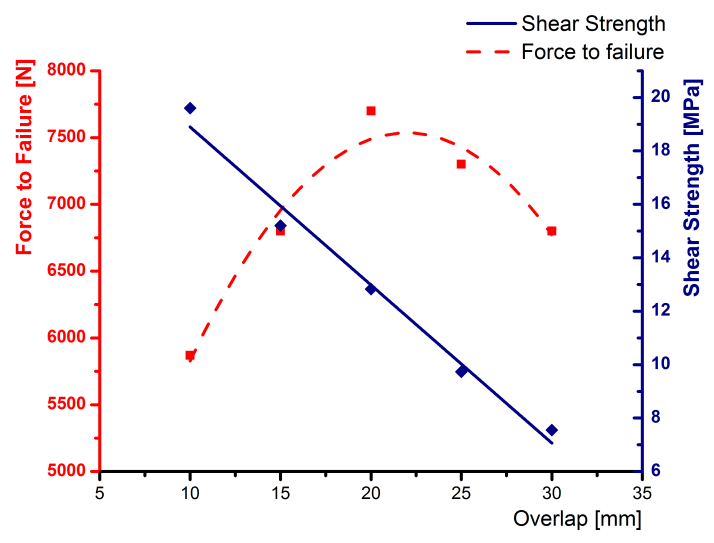

Figure 4. Dependence of shear strength and force to failure on the overlap of the bonded joints (Hysol 9466 adhesive)

the samples were very similar, and no variability of the values was obtained. The results are shown in Table 5. The joints bonded by Hysol 9466 had shear strength higher by $55 \%$ than the joints bonded by Hysol 9492.

In order to determine the influence of the overlap on the total shear strength of the joints, shear tests were carried out on four additional overlaps (10, 15, 20 and $25 \mathrm{~mm}$ ). Only Hysol 9466 was used as the adhesive, because it was predicted that both adhesives would produce similar results. The results (see Fig. 4) proved that the total shear strength of the joints had reversed linear dependence on the overlap area. The highest force to failure was observed in specimens with an overlap of $20 \mathrm{~mm}$. This overlap can be marked as ideal for the mechanical properties of the joints, because bigger overlaps provided smaller shear strength and also smaller force to failure. Although the smaller overlap gave the maximal shear strength, the force to failure was inappropriate.

The results of observations of the fracture areas of the samples fractured by the shear tests are documented in Fig. 5a. Both adhesives showed only the adhesive fracture pattern, i.e. no cohesive or combined types of fracture were observed. Fig. 5b shows a detailed view of a cleavage crack, which was a typical type of crack observed in both types of adhesives.

\section{Conclusion}

We have presented a study of adhesive bonding of aluminium alloy A5754 by epoxy resins. The results have proved that high quality joints can be made using two-component epoxy resins. The shear strength depended on the overlap. The highest shear strength values were observed on an overlap of $10 \mathrm{~mm}$. However, a more important characteristic of bonded joints is their force to failure. In this case, the force to failure was inappropriate, so the ideal overlap was
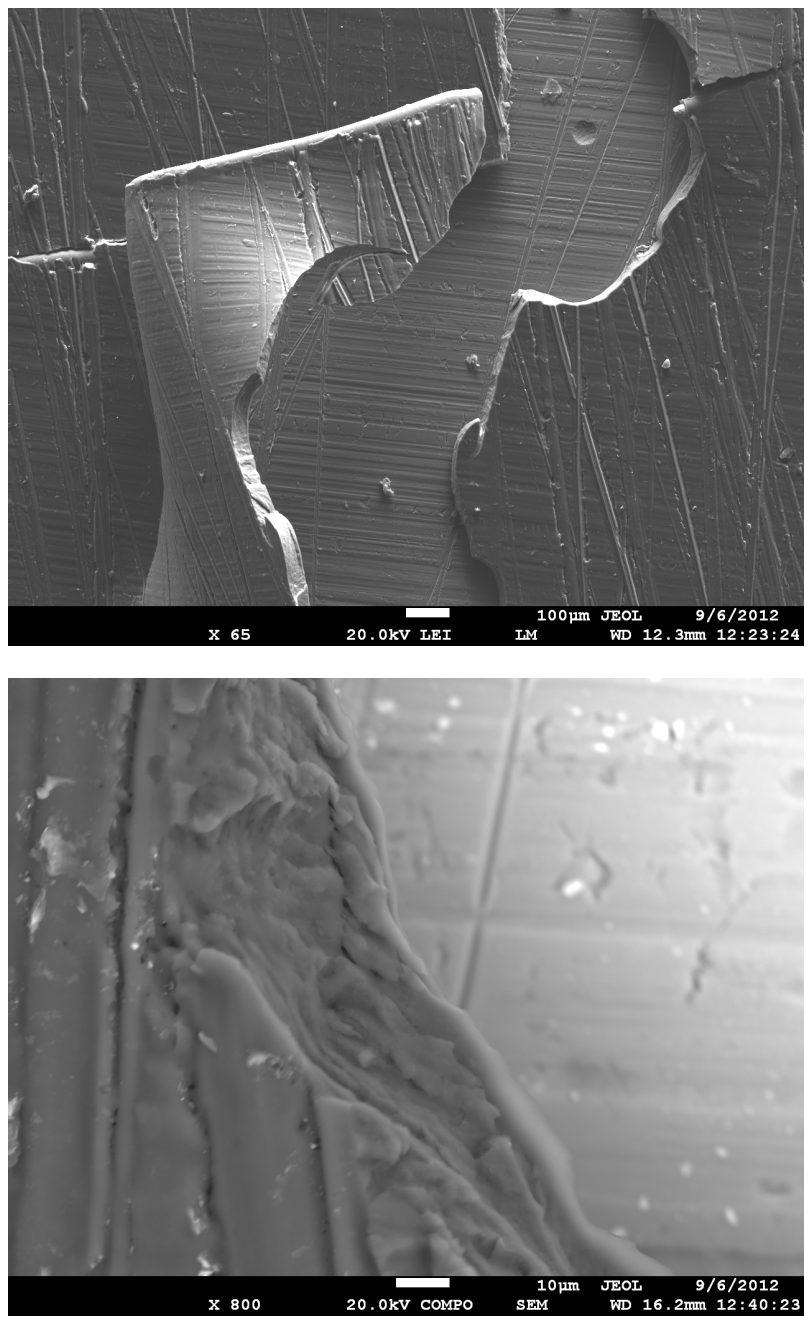

FiguRE 5. The cleavage fracture pattern: a) overall view; b) detailed view of a cleavage crack.

$20 \mathrm{~mm}$, where the maximal force to failure was observed.

The fractographic analysis showed that only an adhesive type of fracture pattern was created in both types of adhesives. The joints were fractures on the interface of the aluminium and adhesive, so the adhesive forces were weaker than the cohesive forces inside the adhesive.

The results provide initial values for a future study. The next step in our research will be to investigate the possibility of hybrid adhesive bonding technology using laser beam welding. This process is well known as laser weld bonding. This hybrid method should provide enhanced mechanical properties and good corrosion resistance, together with satisfactory stress distribution.

Our results have shown that joints made with Hysol 9466 adhesive have satisfactory mechanical properties. However, Hysol 9492 produced better results for thermal stability. Hysol 9492 will be better for laser weld bonding, where problems with porosity are expected. The optimal overlap has been noted for use in our further research. 


\section{ACKNOWLEDGEMENTS}

This paper was prepared with funding from the Young Researchers Support Agency, grant No. 6538 and Scientific Grant Agency VEGA, grant No. 1/0203/11.

\section{REFERENCES}

[1] Hassan, M. F., Megahed, S. M.: Current Advances in Mechanical Design and Production VII. Káhira: Pergamon, 2000.

[2] Pizzi, A.: Handbook of Adhesive Technology Second Edition, Revised and Expanded. New York: Basel, 2003.

[3] Callister, W. D.: Fundamentals of Materials Science and Engineering. New York: Wiley, 2001.

[4] Gierenz, G.: Adhesives and adhesive tapes. Weinheim: Wiley, 2001.

[5] Beevers, A., Steidler, S. M., Duordola, J., Coackley, M.: Analysis of stiffness of adhesive joints in car bodies. Journal of Materials Processing Technology 118:96-101, 2001. 